\title{
Molecular answers to the high failure rate of malaria RDTs
}

\author{
John Waitumbi", Nancy Nyakoe, Linda Muringo, Ismail Mahat, Moses Otiende \\ From Parasite to Prevention: Advances in the understanding of malaria \\ Edinburgh, UK. 20-22 October 2010
}

\section{Background}

Rapid diagnostic tests (RDTs) for malaria are increasingly being used for management of patients. Different studies have shown significant failure rate of RDTs, especially in children and in areas of low malaria transmission. In this study, we sort molecular answers to RDT failure by re-screening RDT negative samples for malaria at genus and species level as well as for diversity of Plasmodium falciparum histidine-rich protein 2 (PfHRP-2) and lactate dehydrogenase (pLDH). PfHRP-2 and $\mathrm{pLDH}$ are the malaria target antigens for the commonly used commercial RDTs.

\section{Methods}

Patients $(\mathrm{n}=1054)$ with high fever but negative for malaria by RDT were recruited for the study from a network of clinical sites in Kenya. For RT-qPCR malaria diagnosis, total nucleic acids were isolated from whole blood and evaluated by a strategy that combines RNA and DNA using $18 \mathrm{~S}$ rRNA primers and probe for malaria genus and species. For diversity of PfHRP-2 and pLDH genes, PCR were subjected to gel electrophoresis to determine amplicons sizes.

\section{Results}

Of the 1054 RDT negative febrile patients, malaria at genus level was detected in 160 patients $(15 \%)$. Of the 160 , half $(52 \%)$ had a parasite density below the limit of detection of RDT in use at the hospital (100 parasites/ $\mu \mathrm{L})$. On speciation, $60 \%$ of the patients had P. falciparum, either alone or in combination with $P$. malarie (7\%), or P. ovale (2\%). $31 \%$ of genus positive malaria could not be speciated. Of the P. falciparum, $56 \%$ had full size PfHRP2 gene (927 bp), 40\% had truncation of up to $325 \mathrm{bp}$ and $1 \%$ appeared not to have PfHRP2

Kenya Medical Research Institute/Walter Reed Project, Kisumu, Kenya gene at all. All parasites had full size pLDH (922 bp) gene.

\section{Conclusion}

It is concluded that, $50 \%$ of the RDT failures are attributable to the detection threshold of the RDTs. It is unclear what impact the truncation of PfHRP2 gene has on sensitivity of RDT. That the failure to detect P.ovale and P.malarie is due to low parasite density commonly associated with these infections and not due to truncation of pLDH gene. Lastly, the unspeciated malaria infections are probably due to higher sensitivity of genus compared to species RT-qPCR.

Published: 20 October 2010

doi:10.1186/1475-2875-9-S2-P56

Cite this article as: Waitumbi et al:: Molecular answers to the high failure rate of malaria RDTs. Malaria Journal 2010 9(Suppl 2):P56.
Submit your next manuscript to BioMed Central and take full advantage of:

- Convenient online submission

- Thorough peer review

- No space constraints or color figure charges

- Immediate publication on acceptance

- Inclusion in PubMed, CAS, Scopus and Google Scholar

- Research which is freely available for redistribution

Submit your manuscript at www.biomedcentral.com/submit
( ) Biomed Central 